\title{
Effect of bromide concentration on the induction period of the cerium-catalysed Belousov-Zhabotinsky oscillating reaction
}

\author{
Kwanjira Panplado $^{\mathrm{a}}$, Premkamon Intasri ${ }^{\mathrm{a}}$, Atchara Sirimungkala ${ }^{\mathrm{a}}$, Titikan Somboon ${ }^{\mathrm{b}, *}$ \\ a Department of Chemistry, Faculty of Science, Khon Kaen University, Nai Muang, Muang District, \\ Khon Kaen 40002 Thailand \\ b Department of Chemistry, Faculty of Engineering, Rajamangala University of Technology Isan, \\ Khonkaen Campus, 150 Srijan Road, Nai Muang, Muang District, Khon Kaen 40000 Thailand
}

*Corresponding author, e-mail: oatsomboon@yahoo.com

Received 23 Aug 2017

Accepted 25 Dec 2017

\begin{abstract}
Temporal oscillations of the cerium(IV)-catalysed Belousov-Zhabotinsky reaction under addition of various $\mathrm{Br}^{-}$concentrations are investigated. The relationship between the induction period and $\mathrm{Br}^{-}$concentration, which is a controlling species in the BZ oscillating reaction, is reported. The oscillations of the Ce(IV) catalyst are followed by using UV-Vis spectrophotometric methods under closed batch and oxygen free systems. Experimental observations demonstrate that increasing $\mathrm{Br}^{-}$concentration decreases the induction period exponentially, whereas it increases the oscillation period linearly. The results reveal that the oscillations without induction period are observed by the addition of $1.0 \times 10^{-2} \mathrm{M} \mathrm{Br}^{-}$concentration. Addition of $\mathrm{Br}^{-}$into the $\mathrm{BZ}$ solution mainly involves the process $\mathrm{A}$ of the FKN mechanism. Numerical results reveal that the addition of $\mathrm{Br}^{-}$increases the production of BrMA, but decreases the induction period.
\end{abstract}

KEYWORDS: Belousov-Zhabotinsky reaction, temporal oscillations, cerium catalyst

\section{INTRODUCTION}

The Belousov-Zhabotinsky (BZ) reaction involves the oxidation of an organic compound, such as malonic acid, by an acidified bromate solution in the presence of a metal ion catalyst, such as cerium ${ }^{1-5}$. The reaction can exhibit the nonlinear phenomena, such as chemical waves and chemical oscillations of the intermediate species. The BZ reaction can be described via the FKN (Field Körös Noyes) mechanism which contains 3 main processes: (A) decrease of $\mathrm{Br}^{-}$concentration and bromination of malonic acid, (B) the autocatalytic reaction of $\mathrm{HBrO}_{2}$ with the concurrent oxidation of $\mathrm{Ce}$ (III) catalyst to $\mathrm{Ce}(\mathrm{IV})$, and $(\mathrm{C})$ regeneration of $\mathrm{Br}^{-}$and the oxidized state of catalyst resetting back to the reduced state. $\mathrm{Br}^{-}$ is an important intermediate species that controls the dynamics of the BZ oscillations because its concentration needs to reach a critical value in order to switch the process from A to B.

One of the main dynamical behaviour before occurring the oscillations in the cerium-catalyst BZ reaction is the induction period, which can be observed in many types of the $\mathrm{BZ}$ system $^{6-19}$. In the classical BZ reaction, the induction period is explained by the time required for the brominated organic products to accumulate, e.g., bromomalonic acid needs to reach a crucial concentration for the onset of oscillations ${ }^{6,8,10}$. This chemical is generated via a bromination reaction between malonic acid in an enol form and bromine. Based on the FKN mechanism, the time to reach a crucial concentration of bromomalonic acid depends on the rate of formation, which strongly depends on the concentration of bromine produced in the process $\mathrm{A}$ and the initial concentration of malonic acid. Bromine is generated in the process A via the reaction of $\mathrm{Br}^{-}$with hypobromous acid under acidic condition. It is consumed by the bromination reaction and its amount is reduced via hydrolysis. Malonic acid plays a dual role in the BZ reaction: reduction of the catalyst and the removal of bromine via bromination reaction ${ }^{8,9}$.

In the bromate-malonic acid-cerium-catalysed $\mathrm{BZ}$ reaction, the induction period depends on the initial concentrations of the BZ reactants (cerium, malonic acid, and bromate concentrations). It becomes shorter with increasing the initial concentra- 
tions of cerium and malonic acid, but it becomes larger with increasing the initial bromate concentration ${ }^{10}$. Induction period can be shortened or suppressed by the addition of bromomalonic acid and the concentration of chloride ion is one parameter that can lengthen the induction period ${ }^{7}$. Other parameters that can enhance the length of induction period are the oxygen ${ }^{11}$, acetonitrile ${ }^{12}$, and $\mathrm{AgNO}_{3}$ concentrations ${ }^{12}$. The lengthening of induction period can also be observed, when methyl ketones were added ${ }^{14-16}$. The increase of the methyl ketone concentration extended the time for reaching the crucial concentration of bromomalonic acid, leading to the enhancement of the induction period ${ }^{14,15}$. Not only induction period, other parameters, i.e., oscillation lifetime and oscillation period are affected by ketone, i.e., acetone ${ }^{16}$. Not only in the bromatemalonic acid-cerium-catalyst BZ system, but induction period can also be observed in other systems such as the bromate-hypophosphite-acetone-dual catalyst system ${ }^{17,18}$ or the system of bromate- 1,4 hydroquinone photoreaction ${ }^{19}$. Also, quenching in dynamics of chemical oscillations can be observed under addition of $\mathrm{Ce}(\mathrm{IV}), \mathrm{HBrO}_{2}, \mathrm{HOBr}$, and $\mathrm{Br}^{-}$in the $\mathrm{BZ}$ reaction ${ }^{20,21}$.

Another type of oscillators that lack of induction period are the bromine-hydrolysis-controlled (BHC) reactions ${ }^{9}$. The main characteristics of $\mathrm{BHC}$ are (i) the absence of an easily brominated organic compound, (ii) $\mathrm{Br}^{-}$concentration is controlled by hydrolysis of bromine, (iii) absence of an induction period. The $\mathrm{BHC}$ oscillators strongly require the removal of $\mathrm{Br}_{2}$ to start the oscillations. $\mathrm{Br}_{2}$ can be removed by addition of acetone or bubbling an inert gas. However, the induction period can be observed in the BHC system under addition of ketone ${ }^{13}$. Hence the time necessary for the bromomalonic acid to accumulate is not the unique explanation for the presence of an induction period in all type of the $\mathrm{BZ}$ reaction. However, the concept of crucial concentration of bromomalonic acid for the induction period can be only used in the classical $\mathrm{BZ}$ reaction, i.e., bromate-malonic acid- $\mathrm{H}_{2} \mathrm{SO}_{4}$-cerium-catalysed BZ oscillating reaction $6,8,14$.

Although many investigations have reported the effect of various chemicals on the induction period $^{6-19}$, the effect of $\mathrm{Br}^{-}$concentration on the induction period of the cerium-catalysed BelousovZhabotinsky oscillating reaction has not been directly reported. In this study various $\mathrm{Br}^{-}$concentrations are initially added in the $\mathrm{BZ}$ solution to investigate their effect on the induction and oscillation periods. The experimental results are discussed based on the rate of bromine and bromomalonic acid production involved in the process $\mathrm{A}$ of the FKN mechanism. This study will be one additional piece of information to understand the oscillation dynamics of the cerium-catalysed $\mathrm{BZ}$ reaction under $\mathrm{Br}^{-}$addition.

\section{MATERIALS AND METHODS}

The temporal oscillations were studied in a closed batch system under nitrogen gas atmosphere. The stock solutions are $0.12 \mathrm{M}$ sodium bromate (Fluka) dissolved in deionized water, $0.40 \mathrm{M}$ malonic acid (Fluka) dissolved in $2 \mathrm{M} \mathrm{H}_{2} \mathrm{SO}_{4}$ (96\%, Carlo Erba), $1.6 \times 10^{-3} \mathrm{M}$ cerium(IV) sulphate tetrahydrate (Riedel-deHaën) dissolved in $2 \mathrm{M} \mathrm{H}_{2} \mathrm{SO}_{4}$. The $\mathrm{BZ}$ reaction is mixed and studied in a reactor equipped with quartz cuvette cells (path length $1 \mathrm{~cm}$ ). The solution was continuously stirred at a constant rate (300 rpm). The temperature in the cell will be kept constant at $25.0 \pm 0.2^{\circ} \mathrm{C}$ by using the Peltier temperature control unit.

To generate the BZ oscillations, $0.75 \mathrm{~cm}^{3}$ of deionized water, $0.75 \mathrm{~cm}^{3}$ of $0.12 \mathrm{M}$ sodium bromate, and $0.75 \mathrm{~cm}^{3}$ of $0.40 \mathrm{M}$ malonic acid are mixed in a cuvette cell. Then the solution was bubbled with nitrogen gas for $15 \mathrm{~min}$. Subsequently, $0.75 \mathrm{~cm}^{3}$ of $1.6 \times 10^{-3} \mathrm{M}$ cerium(IV) sulphate tetrahydrate was pipette into the mixed solution and the absorbance was recorded. The total volume of the BZ solution is $3.00 \mathrm{~cm}^{3}$. The initial concentrations were $0.1 \mathrm{M}$ malonic acid, $0.03 \mathrm{M}$ sodium bromate, $4.0 \times 10^{-4} \mathrm{M}$ cerium(IV) sulphate tetrahydrate, and $1 \mathrm{M} \mathrm{H}_{2} \mathrm{SO}_{4}$. During the $\mathrm{BZ}$ reaction proceeds, nitrogen gas was purged over the BZ solution. All experimental data were recorded in a computer. The spectra for kinetic measurements were taken on Agilent 8453 diode array spectrophotometers. For the investigation of effects of various $\mathrm{Br}^{-}$concentrations, the concentrations of $\mathrm{KBr}$ (UNILAB) were varied in the range of $1.0 \times 10^{-6}$ to $1.0 \times 10^{-2} \mathrm{M}$.

\section{RESULTS AND DISCUSSION}

When all reactants of the $\mathrm{BZ}$ reaction are mixed, the colour of solution is yellow (oxidized form of cerium catalyst). Then the alternate change of Ce(IV) (yellow) to Ce(III) (colourless) is observed. Temporal oscillations of the Ce(IV) catalyst is detected by UVVis spectrophotometer at $400 \mathrm{~nm}\left(A_{400 \mathrm{~nm}}\right)$. A typical temporal trace of the $\mathrm{BZ}$ oscillations without $\mathrm{Br}^{-}$ is shown in Fig. 1. The absorbance value (corresponding to the concentration of Ce(IV)) sharply decrease to the minimum value at point a. Then the absorbance increases a bit and slightly decreases to 


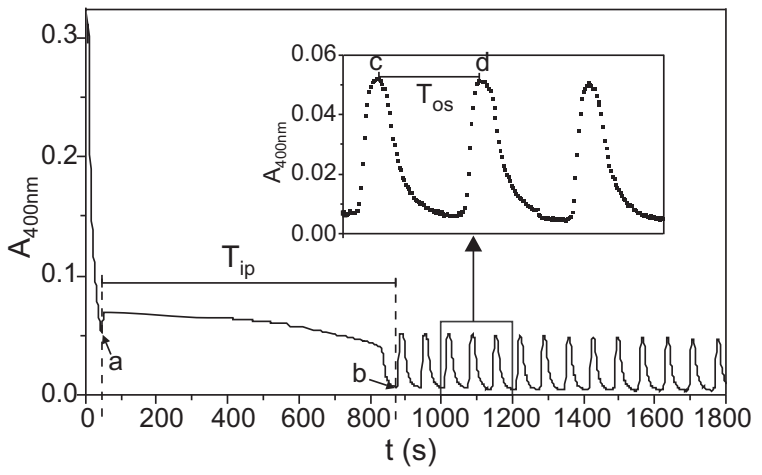

Fig. 1 Temporal trace of oscillations of the ceriumcatalysed $\mathrm{BZ}$ reaction without addition of $\mathrm{Br}^{-}$. Initial concentrations: $0.03 \mathrm{M} \mathrm{NaBrO}_{3}, 0.10 \mathrm{M}$ malonic acid, $4.0 \times 10^{-4} \mathrm{M} \mathrm{Ce}(\mathrm{IV})$, and $1.00 \mathrm{M} \mathrm{H}_{2} \mathrm{SO}_{4}$. The stirring rate and temperature are $300 \mathrm{rpm}$ and $25.0 \pm 0.2^{\circ} \mathrm{C}$, respectively.

point b. Time interval between a and b in Fig. 1 indicates the first oxidation and reduction of the cerium catalyst and will be defined as an induction period $\left(T_{\mathrm{ip}}\right)$. The value of $T_{\mathrm{ip}}$ for the recipe without addition of $\mathrm{Br}^{-}$shown in Fig. 1 is $810 \pm 2 \mathrm{~s}$ (mean of two experiments). After this time interval, the system shows regular oscillations of absorbance (see the inset of Fig. 1). It is noted that the interval between data points in the inset is $1 \mathrm{~s}$. The amplitude of the oscillation peak slightly decreases with time. The oscillation period $\left(T_{\text {os }}\right)$, which is time interval between maximum absorbance values of two consecutive peaks is quite constant during the observation time. The value of $T_{\text {os }}$ for the recipe without $\mathrm{Br}^{-}$is $80 \pm 2 \mathrm{~s}$.

The oscillations of bromate-malonic acidcerium(IV)-catalysed BZ reaction in one cycle (point $\mathrm{c}$ to $\mathrm{d}$ in the inset of Fig. 1) can be divided into 3 processes, corresponding to the field-KörösNoyes (FKN) mechanism ${ }^{1-5}$ : process $\mathrm{A}$-the decrease of $\mathrm{Br}^{-}$to a critical concentration and bromination of malonic acid; process $\mathrm{B}$-the autocatalytic reaction of $\mathrm{HBrO}_{2}$ with the concurrent oxidation of $\mathrm{Ce}(\mathrm{III})$ catalyst to $\mathrm{Ce}(\mathrm{IV})$; process $\mathrm{C}$ the regeneration of $\mathrm{Br}^{-}$and reduction of Ce(IV) to Ce(III) by the organic substrates, i.e., $\mathrm{CH}_{2}(\mathrm{COOH})_{2}$, and $\mathrm{BrCH}(\mathrm{COOH})_{2}$. Oscillation period $\left(T_{\mathrm{os}}\right)$ is the sum of time interval in these three processes (see the inset of Fig. 1). Interval at point a to $\mathrm{b}$ represents the induction period $\left(T_{\mathrm{ip}}\right)$, which is the time for accumulating of bromomalonic acid $\left(\mathrm{BrCH}(\mathrm{COOH})_{2}\right)$ for a crucial concentration ${ }^{6,7}$.

The effect of various $\mathrm{Br}^{-}$concentrations on the

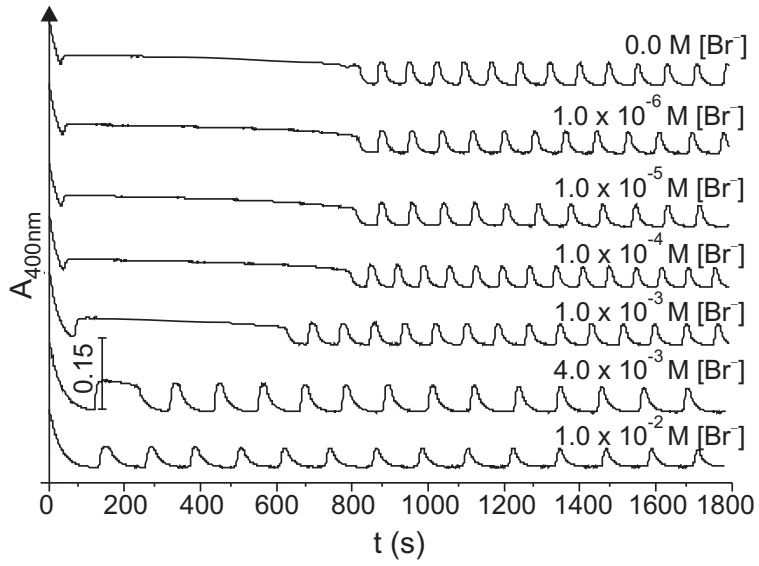

Fig. 2 Temporal trace of oscillations under addition with various $\mathrm{Br}^{-}$concentrations. Initial concentrations of other chemicals are $0.03 \mathrm{M} \mathrm{NaBrO}_{3}, 0.10 \mathrm{M}$ malonic acid, 4.0× $10^{-4} \mathrm{M} \mathrm{Ce}(\mathrm{IV})$, and $1.00 \mathrm{M} \mathrm{H}_{2} \mathrm{SO}_{4}$.

oscillations profile is summarized in Fig. 2. Addition of low $\mathrm{Br}^{-}$concentration $\left(1.0 \times 10^{-6}\right.$ and $1.0 \times$ $10^{-5} \mathrm{M}$ ) results a small decrease in both induction period $\left(T_{\mathrm{ip}}\right)$ and oscillation period $\left(T_{\mathrm{os}}\right)$. The values of $T_{\text {ip }}$ for $1.0 \times 10^{-6}$ and $1.0 \times 10^{-5} \mathrm{M} \mathrm{Br}^{-}$concentration are $808 \pm 2$ and $806 \pm 2 \mathrm{~s}$, respectively (mean of two experiments). The values of $T_{\mathrm{os}}$ are $81 \pm 2$ and $80 \pm 2 \mathrm{~s}$, respectively, for $1.0 \times 10^{-6}$ and $1.0 \times 10^{-5} \mathrm{M} \mathrm{Br}^{-}$concentration (mean of two experiments). However, the results show that the induction period clearly shortens with increasing of $\mathrm{Br}^{-}$concentration in the range $1.0 \times 10^{-4}-4.0 \times$ $10^{-3} \mathrm{M}$. The suppression of induction period can be observed at $1.0 \times 10^{-2} \mathrm{M} \mathrm{Br}^{-}$concentration. In the range of $1.0 \times 10^{-4}-1.0 \times 10^{-2} \mathrm{M} \mathrm{Br}^{-}$concentration, the distance between two consecutive peaks which represented the oscillation period clearly increases with increasing $\mathrm{Br}^{-}$concentration.

Fig. 3 summarizes the value of $T_{\text {ip }}$ as a function of $\mathrm{Br}^{-}$concentration. We found that $T_{\mathrm{ip}}$ exponentially decreases with increasing $\mathrm{Br}^{-}$concentration as follows: $T_{\text {ip }}=101.7+716 \mathrm{e}^{-413\left[\mathrm{Br}^{-}\right]}$. Fig. 4 shows the plot of $T_{\text {os }}$ as a function of $\mathrm{Br}^{-}$concentration. For low $\mathrm{Br}^{-}$concentration $\left(1.0 \times 10^{-6}-1.0 \times 10^{-5} \mathrm{M}\right)$, the values of $T_{\text {os }}$ are not different significantly (the values of $T_{\text {os }}$ are $79 \pm 2,81 \pm 2$, and $80 \pm 2 \mathrm{~s}$, respectively, for $0.0,1.0 \times 10^{-6}$, and $1.0 \times 10^{-5} \mathrm{M} \mathrm{Br}^{-}$ concentrations). However, $T_{\text {os }}$ linearly increases with increasing $\mathrm{Br}^{-}$concentration in the range of $1.0 \times 10^{-4}-1.0 \times 10^{-2} \mathrm{M}$ (see the inset of Fig. 4). The linear relation between $T_{\mathrm{os}}$ and $\mathrm{Br}^{-}$concentration is shown by $T_{\text {os }}=4737.1\left[\mathrm{Br}^{-}\right]+76.0$ with $R^{2}$ of 0.92 . 


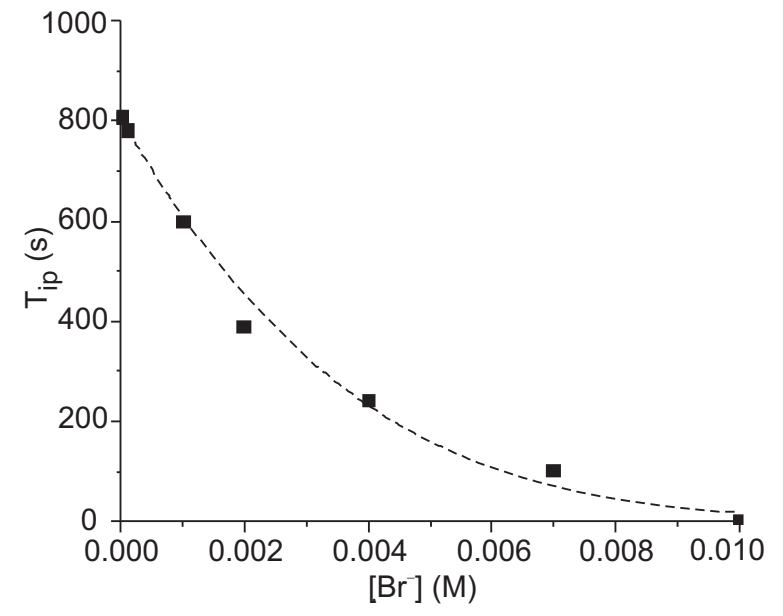

Fig. 3 Induction period $\left(T_{\text {ip }}\right)$ as a function of $\left[\mathrm{Br}^{-}\right]$.

For the classical bromate-malonic-cerium-catalysed BZ reaction, it has been experimentally demonstrated that the induction period occurs until a crucial concentration of the organic brominated species, i.e., bromomalonic acid (BrMA) is reached $6,8,10,14,15,23$. It is well known that BrMA is produced via bromination reaction ${ }^{8}$. Based on the Gyorgyi-Turanyi-Field (GTF) model ${ }^{22}$, the reaction mechanism involved the bromination reaction is summarized and presents in Table 1. Form the reaction mechanism, the production rates of BrMA and $\mathrm{Br}_{2}$ are given by

$$
\begin{aligned}
\frac{\mathrm{d}[\mathrm{BrMA}]}{\mathrm{d} t}= & k_{8}\left[\mathrm{MA}_{\mathrm{Enol}}\right]\left[\mathrm{Br}_{2}\right]+k_{9}\left[\mathrm{MA}_{\mathrm{Enol}}\right][\mathrm{HOBr}] \\
\frac{\mathrm{d}\left[\mathrm{Br}_{2}\right]}{\mathrm{d} t}= & k_{1}[\mathrm{HOBr}]\left[\mathrm{Br}^{-}\right]\left[\mathrm{H}^{+}\right]-k_{-1}\left[\mathrm{Br}_{2}\right] \\
& -k_{8}\left[\mathrm{MA}_{\mathrm{Enol}}\right]\left[\mathrm{Br}_{2}\right] .
\end{aligned}
$$

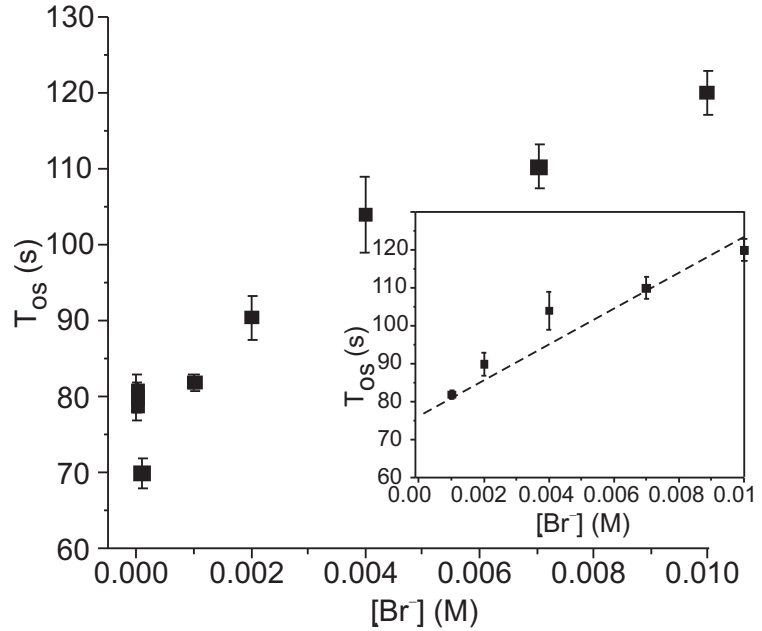

Fig. 4 Oscillation period $\left(T_{\text {os }}\right)$ as a function of $\left[\mathrm{Br}^{-}\right]$. The inset picture presents the linear relation of $T_{\mathrm{os}}$ and $\left[\mathrm{Br}^{-}\right]$.

The production rate of BrMA strongly depends on concentration of $\mathrm{MA}_{\mathrm{Enol}}, \mathrm{Br}_{2}$, and $\mathrm{HOBr}$. $\mathrm{MA}_{\text {Enol }}$ is an important intermediate species in the bromination reaction. The rate of change of $\mathrm{MA}_{\text {Enol }}$ can be written as follows:

$$
\begin{aligned}
& \frac{\mathrm{d}\left[\mathrm{MA}_{\text {Enol }}\right]}{\mathrm{d} t}=k_{7}[\mathrm{MA}]-k_{-7}\left[\mathrm{MA}_{\text {Enol }}\right] \\
& \quad-k_{8}\left[\mathrm{Br}_{2}\right]\left[\mathrm{MA}_{\text {Enol }}\right]-k_{9}[\mathrm{HOBr}]\left[\mathrm{MA}_{\text {Enol }}\right] .
\end{aligned}
$$

The steady-state approximation for the enol form $\left(\mathrm{d}\left[\mathrm{MA}_{\mathrm{Enol}}\right] / \mathrm{d} t=0\right)$ was employed to prove the bromination reaction ${ }^{8}$. By using this approximation, the concentration of $\mathrm{MA}_{\text {Enol }}$ equals $\left(k_{7}[\mathrm{MA}]\right) /\left(k_{-7}+k_{8}\left[\mathrm{Br}_{2}\right]+k_{9}[\mathrm{HOBr}]\right) . \quad \mathrm{MA}_{\mathrm{Enol}}$ is substituted in (1) and the production rate of BrMA

Table 1 Chemical reactions involved bromination in process A of the FKN mechanism.

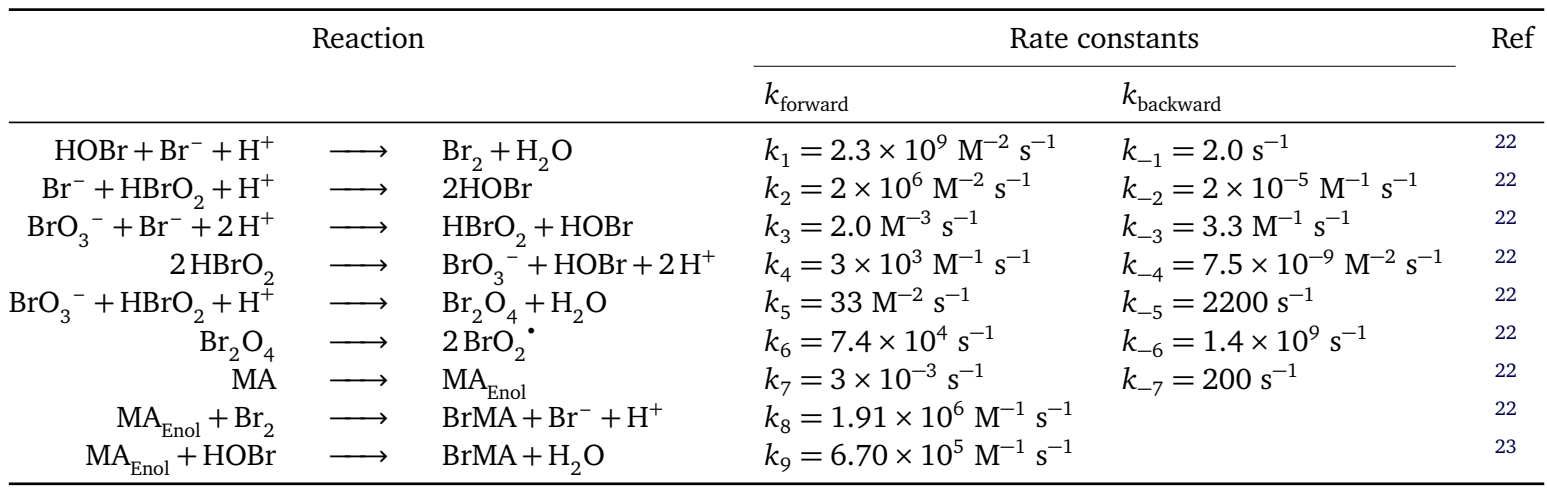

MA: $\mathrm{CH}_{2}(\mathrm{COOH})_{2} ; \mathrm{MA}_{\mathrm{Enol}}$ : $(\mathrm{HOOC}) \mathrm{CH}=\mathrm{C}(\mathrm{OH})_{2}$; $\mathrm{BrMA}: \mathrm{BrCH}(\mathrm{COOH})_{2}$. 

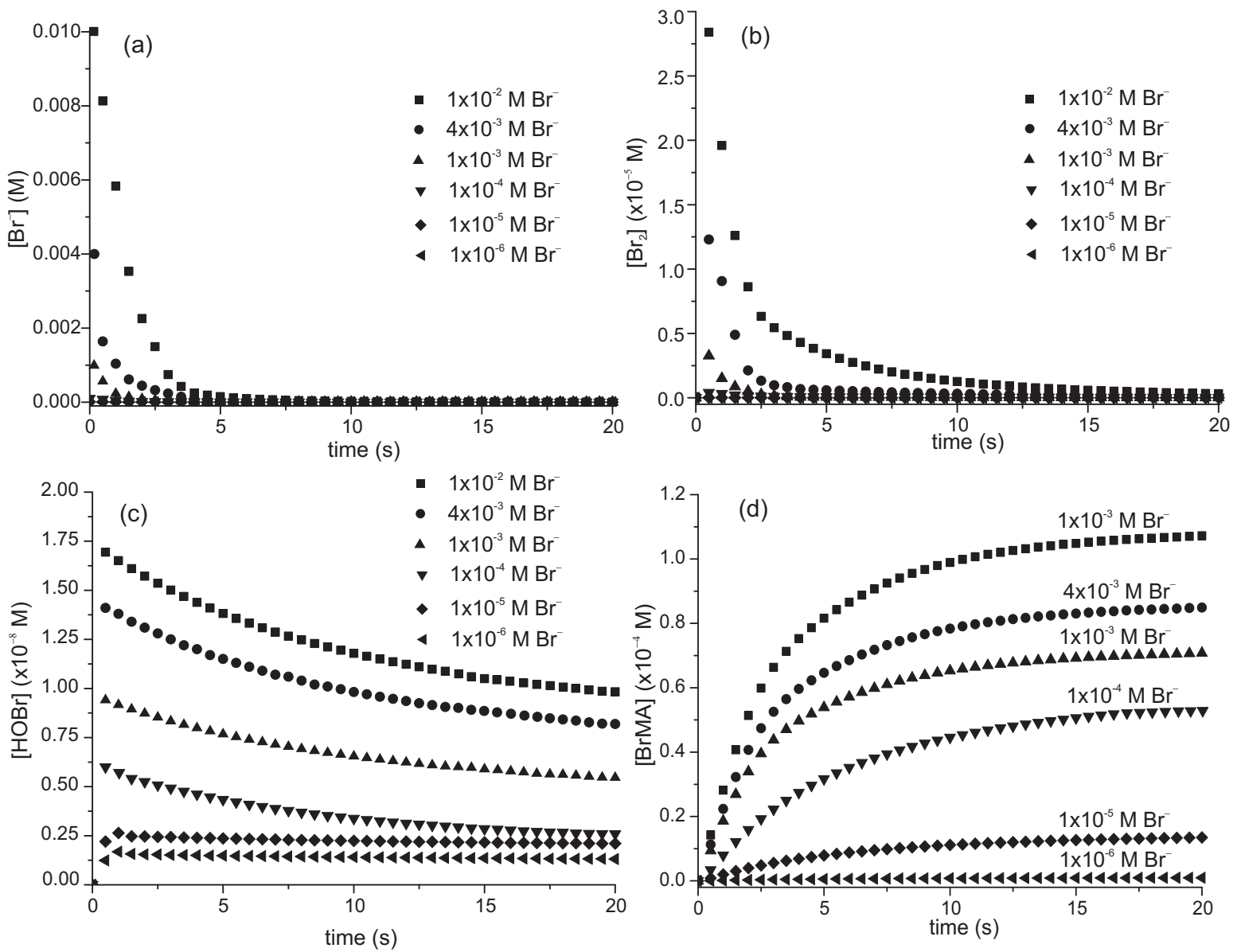

Fig. 5 Numerical results presented the concentration of (a) $\mathrm{Br}^{-}$, (b) $\mathrm{Br}_{2}$, (c) $\mathrm{HOBr}$, and (d) BrMA as a function of time under addition of different initial $\mathrm{Br}^{-}$concentrations ranged of $10^{-6}-10^{-2} \mathrm{M}$. Initial concentrations of other reactants: $\left[\mathrm{BrO}_{3}{ }^{-}\right]_{0}=0.03 \mathrm{M},[\mathrm{MA}]_{0}=0.10 \mathrm{M},\left[\mathrm{H}_{2} \mathrm{SO}_{4}\right]_{0}=1.00 \mathrm{M}$.

can be expressed as follows:

$$
\left.\frac{\mathrm{d}[\mathrm{BrMA}}{\mathrm{d}]} t=\frac{k_{7} k_{8}[\mathrm{MA}]\left[\mathrm{Br}_{2}\right]+k_{7} k_{9}[\mathrm{MA}][\mathrm{HOBr}]}{k_{-7}+k_{8}\left[\mathrm{Br}_{2}\right]+k_{9}[\mathrm{HOBr}}\right] \text {. }
$$

The steady-state approximation reveals that the production of BrMA strongly depends on the concentration of MA, $\mathrm{Br}_{2}$ and $\mathrm{HOBr}$.

The experimental results in Fig. 3 reveal that the induction period decreases with the increase of $\mathrm{Br}^{-}$concentration. The assumption for explaining the results is that the direct addition of $\mathrm{Br}^{-}$will enhance the production of $\mathrm{Br}_{2}$ and $\mathrm{HOBr}$, consequently increases the production of BrMA. To prove this assumption, a simulation by numerical calculation based on the reaction mechanism shown in Table 1 is carried out. The numerical results shown in Fig. 5a reveal that the added $\mathrm{Br}^{-}$concentration decreases with time due to it acts as a reactant for production of $\mathrm{Br}_{2}$ and $\mathrm{HOBr}$. The concentrations of $\mathrm{Br}_{2}$ and $\mathrm{HOBr}$ increase with increasing of $\mathrm{Br}^{-}$as shown in Fig. 5b,c. $\mathrm{Br}_{2}$ sharply decreases, but $\mathrm{HOBr}$ slowly decreases with time. The concentration of BrMA clearly increases with increasing the $\mathrm{Br}^{-}$concentration as presented in Fig. 5d. The numerical results confirm that the increase of $\mathrm{Br}^{-}$concentration enhances the production of BrMA, which can shorten the induction period of the bromatemalonic-cerium-catalysed BZ reaction. However, a simulation by numerical integration using all chemical reactions in either the GTF model ${ }^{22}$ or the MBM model $^{23}$ that would give a solid interpretation about the effect of $\mathrm{Br}^{-}$on the induction period will be carried out in further work. Some reactions between $\mathrm{Ce}(\mathrm{IV})$ and organic species in such models ${ }^{22,23}$ have to be proved before using the model to explain the oscillation dynamics under $\mathrm{Br}^{-}$addition.

The results in Fig. 4 shows that the values of $T_{\text {os }}$ are not significantly different for low $\mathrm{Br}^{-}$con- 


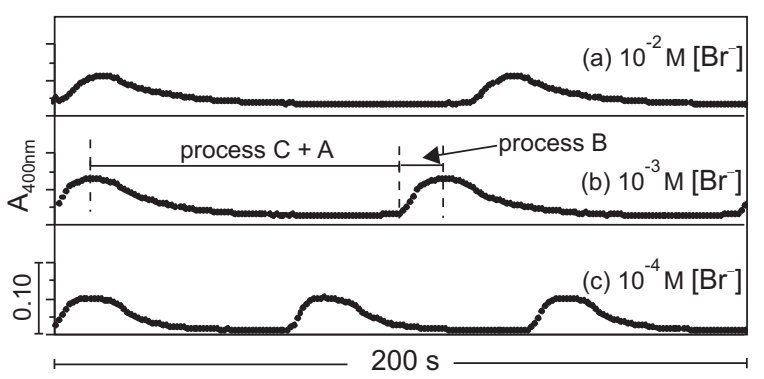

Fig. 6 Effects of $\mathrm{Br}^{-}$concentration on each process of the FKN mechanism. Initial concentrations of other chemicals are $0.03 \mathrm{M} \mathrm{NaBrO}_{3}, 0.10 \mathrm{M}$ malonic acid, $4.0 \times 10^{-4} \mathrm{M}$ $\mathrm{Ce}(\mathrm{IV})$, and $1.00 \mathrm{M} \mathrm{H}_{2} \mathrm{SO}_{4}$.

centration, it linearly increases with increasing $\mathrm{Br}^{-}$ concentration in the range of $1.0 \times 10^{-3}-1.0 \times 10^{-2} \mathrm{M}$ $\mathrm{Br}^{-}$concentration. The experimental results can be explained by considering the fact that the direct addition of $\mathrm{Br}^{-}$into the $\mathrm{BZ}$ reaction will enhance the amount of $\mathrm{Br}^{-}$in the $\mathrm{BZ}$ solution. Addition of $\mathrm{Br}^{-}$ into the $\mathrm{BZ}$ system makes a longer time for removing $\mathrm{Br}^{-}$in the process A because the $\mathrm{BZ}$ oscillating reaction requires the decrease in $\mathrm{Br}^{-}$concentration to the critical $\mathrm{Br}^{-}$concentration for switching the reaction process from $A$ to $\mathrm{B}^{5}$. Consequently, the oscillation period is lengthened. Fig. 6a-c shows the length of each process for different $\mathrm{Br}^{-}$concentration. The results in Fig. 6 reveal that time in process $\mathrm{C}$ and $\mathrm{A}$ increases with increasing the $\mathrm{Br}^{-}$concentration, whereas durations in the process $\mathrm{B}$ of each $\mathrm{Br}^{-}$concentration are not significantly different. It is consistent with previous report that the oscillation in one cycle of the BZ oscillation takes time in the process $\mathrm{A}$ higher than other processes ${ }^{16}$. This indicates that the oscillation period strongly depends on the duration in the process $\mathrm{A}$, which is the decrease of $\mathrm{Br}^{-}$concentration. This result confirms that addition of $\mathrm{Br}^{-}$mainly affects on the process $\mathrm{A}$, resulting in the lengthening of the oscillation period.

\section{CONCLUSIONS}

$\mathrm{Br}^{-}$is one of the most important chemical species controlling the dynamics of the bromate-malonic acid-cerium-catalyst BZ oscillating reaction. Our experimental results demonstrate that the induction period of temporal oscillations in the ceriumcatalysed BZ reaction are significantly shorter and finally suppressed, when the $\mathrm{Br}^{-}$concentration is increased. Introduction of $\mathrm{Br}^{-}$into the $\mathrm{BZ}$ solution mainly involves on the process A of the FKN mech- anism. Addition of $\mathrm{Br}^{-}$clearly affects the induction period and oscillation period. The numerical results agree with the hypothesis that the addition of $\mathrm{Br}^{-}$ can enhance the production of BrMA, resulting in the decrease of induction period. The increase of $\mathrm{Br}^{-}$concentration in the $\mathrm{BZ}$ solution results in the enhancement of oscillation period. Under addition of $\mathrm{Br}^{-}$, the $\mathrm{BZ}$ reaction would take longer time in the process $\mathrm{A}$ to reduce $\mathrm{Br}^{-}$concentration, causing the increase of oscillation period. Our experimental observation is one additional piece of information to understand the induction period. Also, our recipe will be useful for analytical field using oscillating reaction for determining interested analytes since it provides the oscillations without induction period.

Acknowledgements: Kwanjira Panplado wishes to thank Science Achievement Scholarship of Thailand for financial support. This work was also financially supported by Faculty of Engineering, Rajamangala University of Technology Isan, Khon Kaen Campus. Authors would like to express gratitude to Department of Chemistry, Faculty of Science, Khon Kaen University for UV-Vis spectrophotometer. Authors thank Dr Paramust Juntarakod from the Department of Mechatronic Engineering, Faculty of Engineering, Rajamangala University of Technology Isan, Khonkaen Campus for suggestion in the part of numerical calculation.

\section{REFERENCES}

1. Field RJ, Kőrös E, Noyes RM (1972) Oscillations in chemical systems. II. Through analysis of temporal oscillations in the bromate-cerium-malonic acid system. J Am Chem Soc 94, 8649-64.

2. Field RJ, Noyes RM (1974) Oscillations in chemical systems. V. Quantitative explanation of band migration in the Belousov-Zhabotinskii reaction. $J \mathrm{Am}$ Chem Soc 94, 2001-6.

3. Field RJ, Noyes RM (1977) Oscillations in chemical systems. 18. Mechanisms of chemical oscillators: conceptual bases. Accounts Chem Res 10, 214-21.

4. Epstein IR, Pojman JA (1998) An Introduction to Nonlinear Chemical Dynamics "Oscillations, Waves, Patterns, and Chaos", Oxford Univ Press, New York.

5. Scott SK (1994) Oscillations, Waves, and Chaos in Chemical Kinetics, Oxford Univ Press, New York.

6. Burger M, Koros E (1980) Condition for the onset of chemical oscillations. J Phys Chem 84, 496-500.

7. Jacobs SS, Epstein IR (1976) Effects of chloride ion on oscillations in the bromate-cerium-malonic acid system. J Am Chem Soc 98, 1721-4.

8. Sirimungkala A, Försterling $\mathrm{H}$, Dlask V, Field RJ (1999) Bromination reactions important in the mechanism of the Belousov-Zhabotinsky system. J Phys Chem 103, 1038-43. 
9. Field RJ, Boyd PM (1985) Bromine-hydrolysis control in the cerium ion-bromate ion-oxalic acid-acetone Belousov-Zhabotinskii oscillator. $J$ Phys Chem 89, 3707-14.

10. Cadena A, Pérez N, Ágreda JA, Barragán D (2005) Understanding the induction period of the BelousovZhabotinsky reaction. J Braz Chem Soc 16, 214-9.

11. Treindl L, Ruoff P, Kvernberg PO (1997) Influence of oxygen and organic substrate on oscillations and autocatalysis in the Belousov-Zhabotinsky reaction. $J$ Phys Chem A 101, 4606-12.

12. Petrascu AM, Koch MHJ, Försterling H (1999) Effect of oxygen on the Belousov-Zhabotinsky reaction at low cerium concentrations. J Phys Chem A 103, 6757-65.

13. Berenstein I, Ágreda J, Barragán D (1999) Induction period in the $\mathrm{BrO}_{3}{ }^{-}$, $\mathrm{Ce}(\mathrm{III}), \mathrm{H}_{2} \mathrm{SO}_{4}$, oxalic acid and ketone oscillating reaction. Phys Chem Chem Phys 1, 4601-3.

14. Berenstein I, Ágreda J, Barragán D (1999) Effect of methyl ketones in the Belousov-Zhabotinskii reaction. $J$ Phys Chem 103, 9780-2.

15. Berenstein I, Barragán D (2004) Additive effects of methyl ketones in the Belousov-Zhabotinsky reactions. J Braz Chem Soc 15, 844-8.

16. Somboon T, Wirairat P, Müller SC, Kheowan O (2015) The effect of acetone on the dynamics of temporal oscillations and waves in the ruthenium-catalyzed Belousov-Zhabotinsky reaction. Phys Chem Chem Phys 17, 7114-21.

17. Orbán M, Kurin-Csörgei K, Zhabotinsky AM, Epstein IR (2001) A new chemical system for studying pattern formation: Bromate-hypophosphite-acetonedual catalyst. Faraday Discuss 120, 11-9.

18. Szalai I, Kurin-Csörgei K, Horváth V, Orbán M (2006) New experimental data and mechanistic studies on the bromate-dual substrate-dual catalyst batch oscillator. J Phys Chem A 110, 6067-72.

19. Bell JG, Green JR, Wang J (2014) Complex reaction dynamics in the cerium-bromate-2-methyl-1,4hydroquinone photoreaction. J Phys Chem A 118, 9795-800.

20. Hynne F, Sørensen PG (1987) Quenching of chemical oscillations. J Phys Chem 91, 6573-5.

21. Sørensen PG, Hynne F (1989) Amplitudes and phases of small-amplitude Belousov-Zhabotinskii oscillations derived from quenching experiments. J Phys Chem 93, 5467-74.

22. Györgyi L, Turányi T, Field RJ (1990) Mechanistic details of the oscillatory Belousov-Zhabotinskii reaction. J Phys Chem 94, 7162-70.

23. Hegedűs L, Wittmann M, Noszticzius Z, Yan S, Sirimungkala A, Försterling HD, Field RJ (2001) HPLC analysis of complete BZ systems. Evolution of the chemical composition in cerium and ferroin catalysed batch oscillators: experiments and model calculations. Faraday Discuss 120, 21-38. 